\title{
Effect of De-Ashing Strategies on Pore Structure and Electrochemical Performance of Activated Carbons for Supercapacitors
}

\author{
Weiwei KANG ${ }^{1,2}$, Guangxu HUANG ${ }^{1,3}{ }^{*}$, Qianhao GENG ${ }^{1}$, Wentao HOU ${ }^{1}$, \\ Youheng YAO ${ }^{1}$, Bing XU ${ }^{1}$, Baolin XING ${ }^{1,3}$, Chuanxiang ZHANG ${ }^{1,3,4}$
}

\author{
${ }^{1}$ College of Chemistry and Chemical Engineering, Henan Polytechnic University, Jiaozuo 454003, China \\ ${ }^{2}$ School of Chemistry and Chemical Engineering, Southeast University, Nanjing 211189, China \\ ${ }^{3}$ Collaborative Innovation Center of Coal Work Safety, Henan Province \\ ${ }^{4}$ Henan Key Laboratory for Green and Efficient Mining \& Comprehensive Utilization of Mineral Resources, Henan \\ Polytechnic University
}

crossref http://dx.doi.org/10.5755/j01.ms.24.3.18505

\section{Received 01 July 2017; accepted 12 October 2017}

\begin{abstract}
The ash was removed before or after carbonization of potassium humate to investigate the effect of ash removal methods on pore structure and electrochemical performance of activated carbons for supercapacitors. The activated carbons were prepared by direct carbonization of potassium humate at $700{ }^{\circ} \mathrm{C}$ for 1 hour under $\mathrm{N}_{2}$ atmosphere with different de-ashing strategies. It was found that ash removal before carbonization was an effective strategy to reduce the ash content of the corresponding activated carbon. When de-ashing treatment was adopted after carbonization, part of the ash in activated carbon was coated with carbon and could not be removed through acid soaking. Moreover, ash removal before carbonization could better contribute to creating the micropores and the ash removed after carbonization performed as templates to mainly generate mesopores. The activated carbon with ash removed before carbonization as electrodes delivered a specific capacitance of $164.84 \mathrm{~F} / \mathrm{g}$ at a current density of $50 \mathrm{~mA} / \mathrm{g}$, and exhibited typical electric double layer capacitive performance as well as lower leakage current of $15.3 \mu \mathrm{A}$.

Keywords: ash removal, activated carbon, potassium humate, template, mesopores.
\end{abstract}

\section{INTRODUCTION}

Electric double layer capacitors (EDLCs), also known as supercapacitors, have been extensively investigated due to their excellent properties such as high power density, high coulombic efficiency, short charging time and long cycle life $[1,2]$. EDLCs currently fill the gap between batteries and conventional capacitors [3-8], and have widespread applications in hybrid vehicles, memory backup - system $[6,7]$, elevator, locomotives [9], and so on. EDLCs store charges in the double layer formed at the electrolyteelectrode interface $[3,7,10,11]$, and their electrochemical performances strongly depend on the properties of the electrode materials, including specific surface area, pore size distribution, surface chemistry and electronic conductivity [12]. Activated carbon is considered as one of the most promising electrode materials for EDLCs because of its high specific surface area, well-developed and adjustable porous structure, high conductivity, excellent chemical stability and low cost $[4,13]$.

Ash in activated carbon has negative impacts on the electrochemical properties of the corresponding EDLCs, including increase in leakage current and decrease in electrochemical cycling stability [12]. Fortunately, the mineral matter in precursors can function as templates for porosity formation of the resultant activated carbons [9]. Activated carbon prepared from rice husk, was basically mesoporous, which was obtained from leaching of the mineral component of silica, and exhibited a considerable specific capacitance of $120 \mathrm{~F} / \mathrm{g}$ in $\mathrm{EMIm} \mathrm{BF}_{4}$ [14]. Qu [15] prepared corncob residues based porous carbon with high capacitance of $314 \mathrm{~F} / \mathrm{g}$ and superb cycling stability in $6 \mathrm{M}$ $\mathrm{KOH}$ electrolyte, and found that the process of ash removal was efficient for pore-forming, especially so for welldeveloped micropores. However, to the best of my knowledge, there are few studies available regarding the effects of the de-ashing strategies on the surface area and pore size distribution of the resulting activated carbons, which play a crucial role in determining their electrochemical performances.

Activated carbons for supercapacitors have been prepared from different precursors, including coal [3], coal tar pitch [16] and biomass [17]. Humic acid (HA), a kind of biomasses, consisting of a skeleton of aromatic units crosslinked by oxygen-containing functional groups [18, 19], has been becoming a promising precursor for activated carbon preparation. Oxygen-rich and hierarchical porous carbons were prepared from humic acid through $\mathrm{KOH}$ or $\mathrm{ZnCl}_{2}$ activation method, delivering high specific capacitance, high rate capabilities and excellent cycling stabilities [19-21]. Potassium humate, a neutralized product of $\mathrm{KOH}$ and $\mathrm{HA}$ with a $\mathrm{KOH} / \mathrm{HA}$ mass ratio of about 0.12 , can be used as precursor to synthesize highly porous carbons by single-step carbonization, which exhibited a high specific capacitance of $232 \mathrm{~F} / \mathrm{g}\left(26.1 \mu \mathrm{F} / \mathrm{cm}^{2}\right)$ at a constant charge/discharge current of $0.5 \mathrm{~A} / \mathrm{g}$ [22]. Obviously, the ash

\footnotetext{
* Corresponding author. Tel.: +86-10-0391 3986816; fax: +86-10-0391 3986810. E-mail address: guangxu1369@163.com (G. Huang)
} 
content of as-prepared porous carbons greatly depends on that of potassium humate due to the relatively weak activation with small amount of potassium. In other words, potassium humate is an appropriate precursor for preparing activated carbons as EDLCs electrodes and, more importantly, for studying the effects of de-ashing strategies on their pore structure simultaneously.

In this paper, the commercial potassium humate with high ash content is adopted as precursor to prepare activated carbons by direct carbonization with ash removed before or after carbonization, respectively. The effects of ash removal strategies on the specific surface area and pore size distribution of as-prepared activated carbons are studied, and their electrochemical properties are also investigated in detail.

\section{EXPERIMENTAL}

\subsection{Preparation of activated carbons}

The commercial potassium humate with ash content of $20 \%$ was purchased from Shuanglong Co., Ltd (Xinjiang, China) and its ultimate analysis is shown in Table 1. The activated carbons were prepared by direct carbonization of potassium humate at $700^{\circ}$ for 1 hour with a heating rate of $5{ }^{\circ} \mathrm{C} / \mathrm{min}$ under $\mathrm{N}_{2}$ flow. The ash was removed before or after carbonization of commercial potassium humate through hydrochloric acid and hydrofluoric acid soaking with a volume ratio of $1: 1$. The carbonized materials were washed with diluted hydrochloric acid and deionized water, and dried at $120^{\circ}$ for 2 hours. The obtained activated carbons with ash removed before or after carbonization were referred as $\mathrm{AC} 1$ and $\mathrm{AC} 3$, respectively. Meanwhile, activated carbon prepared without ash removed was nominated as AC2.

Table 1. Ultimate analysis of potassium humate

\begin{tabular}{|c|c|c|c|}
\hline $\mathrm{C}_{\mathrm{daf}}, \%$ & $\mathrm{H}_{\mathrm{daf}}, \%$ & $(\mathrm{O}+\mathrm{S}) *$ daf, $\%$ & $\mathrm{~N}_{\mathrm{daf}} \%$ \\
\hline 44.98 & 3.26 & 50.85 & 0.91 \\
\hline $\begin{array}{l}\text { Notes: ad - air dried basis; } \\
* \text { - difference method. }\end{array}$ \\
* dry basis; daf-dry ash free basis; \\
\hline
\end{tabular}

\subsection{Characterization}

The elemental composition of porous carbons was analyzed by an elemental analyzer (Vario Macro Cube, Germany). A silica crucible and a muffle furnace were used to estimate ash content. X-ray diffraction (XRD) patterns were collected on a Rigaku Smart-Lab X-ray diffractometer at a scan rate of $10^{\circ} \mathrm{C} / \mathrm{min}$. $\mathrm{N}_{2}$ adsorption/desorption isotherms were measured using a Quantachrome AutosorbiQ-MP analyzer at $77 \mathrm{~K}$. The specific surface area $\left(S_{\mathrm{BET}}\right)$ was calculated from the isotherms using Brunauer-EmmettTeller method. The total pore volume $\left(V_{\mathrm{t}}\right)$ was estimated from the single point adsorption $\left(P / P_{0}=0.99\right)$ and pore size distributions (PSD) were derived from density functional theory (DFT). The micropore volume ( $\left.V_{\text {mic }}\right)$ was determined by the t-plot method and the mesopore volume $\left(V_{\text {mes }}\right)$ was calculated by the difference of total pore volume and micropore volume. Prior to test, the samples were degassed at $200{ }^{\circ} \mathrm{C}$ for 10 hours to remove the water vapor and other foreign gas matters. The morphology of the samples was observed by scanning electron microscope (SEM, JSM-
6390LV, JEOL). X-ray photoelectron spectroscopy (XPS, Thermo ESCALAB 250Xi) was used to investigate the surface chemical composition.

\subsection{Electrodes preparation and electrochemical measurements}

A two-electrode cell was used for electrochemical tests with a $3 \mathrm{M} \mathrm{KOH}$ solution as the electrolyte. The electrodes were fabricated by mixing $85 \mathrm{wt} . \%$ activated carbon powders with $10 \mathrm{wt} \%$ of acetylene black and $5 \mathrm{wt} \%$ of polytetrafluorene ethylene (PTFE) binder. The galvanostatic charge-discharge (GCD), cyclic voltammetry (CV) and Leakage current (LC) were performed on an Arbin SCTS Instrument (CSCT, Arbin, USA). The gravimetric capacitances $(\mathrm{F} / \mathrm{g})$ were calculated from the discharge curves according to:

$C_{\mathrm{g}}=2(I \Delta t) /(m \Delta V)$,

where $I, \Delta t, \mathrm{~m}$ and $\Delta V$ are the discharge current, A; discharge time, $\mathrm{s}$; the mass, $\mathrm{g}$ of the active materials in the single electrode and the discharge voltage, respectively.

\section{RESULTS AND DISCUSSION}

\subsection{Characterization of pore structure}

The ash contents of the three activated carbons are listed in Table 2. The commercial potassium humate precursor has high ash content of $20 \%$, resulting in relatively high ash content $(11.6 \%)$ of the corresponding activated carbon (AC2) without ash removal in the preparation process.

Table 2. Ash contents of the activated carbons

\begin{tabular}{|c|c|c|c|}
\hline Samples & AC1 & AC2 & AC3 \\
\hline Ash, $\%$ & 6.3 & 11.6 & 9.4 \\
\hline
\end{tabular}

The three carbons have an order of $\mathrm{AC} 1<\mathrm{AC} 3<\mathrm{AC} 2$ in terms of ash content. The result indicates that ash removal before rather than after carbonization is an effective strategy to reduce the ash content of the corresponding activated carbons, and also suggests that part of the ash in AC2 is coated with carbon and cannot be removed through acid soaking.

As shown in Fig. 1, activated carbons all exhibit two broad peaks at around $2 \theta=22^{\circ}$ and $43^{\circ}$, which are attributed to the reflection in the (002) plane and (100) plane of aromatic layers respectively, indicating a porous structure with a relatively low degree of graphitization [23].

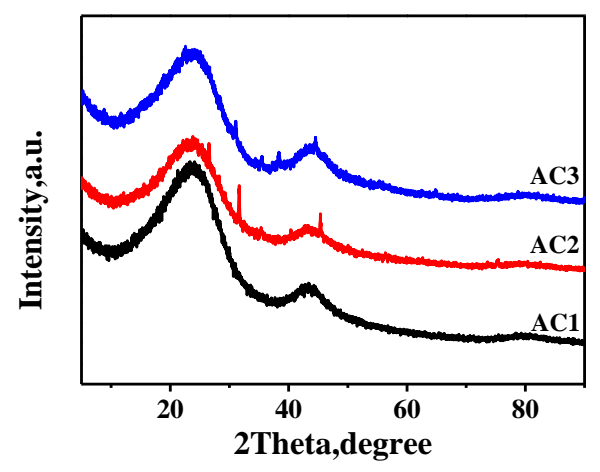

Fig. 1. XRD patterns of activated carbons 
For AC2 and AC3, there are some sharp peaks, which is assigned to the mineral matters.

Fig. 2 a shows the $\mathrm{N}_{2}$ adsorption/desorption isotherms of activated carbons. The isotherms of $\mathrm{AC} 1$ and $\mathrm{AC} 3$ exhibit characteristics of type IV curve, showing a sharp increase in adsorptive volumes at low relative pressures while a relatively smooth increase at high relative pressure, and exhibiting pronounced hysteresis loops. The results above demonstrate the presence of certain amount of micropores and mesopores in AC1 and AC3. The $\mathrm{N}_{2}$ adsorption/desorption isotherm of AC2 exhibits combined characteristics of type I/IV curve. The obvious hysteresis loop indicates the existence of a relatively large percentage of mesopores, and the almost vertical tail at a relative pressure near to 0.95 denotes the presence of macroporosity $[12,13,20]$.
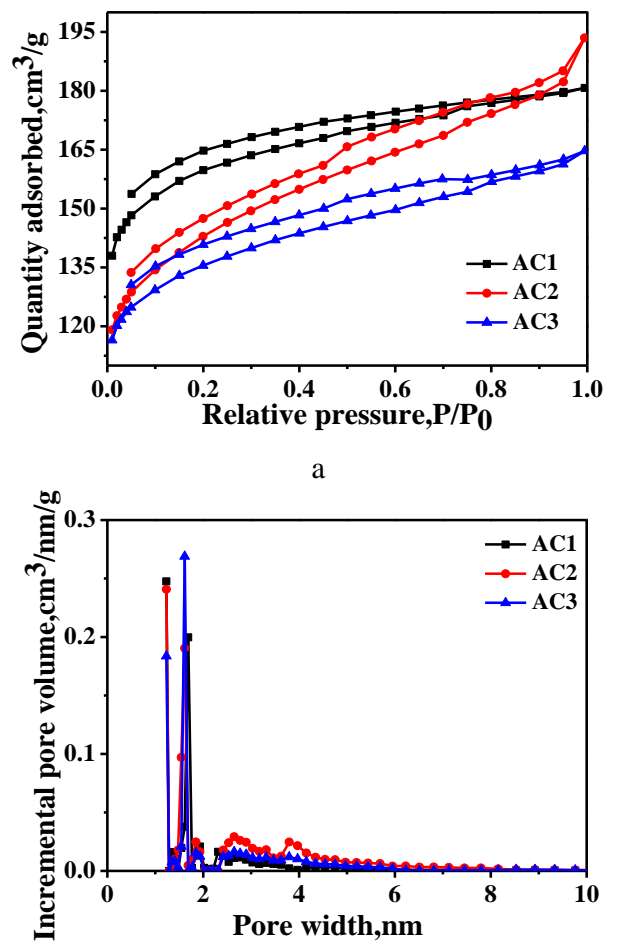

b

Fig. 2. $\mathrm{a}-\mathrm{N}_{2}$ adsorption-desorption isotherms of activated carbons; $\mathrm{b}$ - pore size distribution of activated carbons

The PSD curves are shown in Fig. 2 b and demonstrate activated carbons possess hierarchical pore structure with micropores less than $1.8 \mathrm{~nm}$ and mesopores in the range of 2.3 to $6 \mathrm{~nm}$. It is well known that the micropores can accommodate electrolyte ions to achieve high capacitance, mesopores act as channels to facilitate ion transportation within the carbon framework, and macropores serve as ionbuffering reservoirs to reduce diffusion distance for electrolyte ions diffusing into the interior surface $[9,10]$. Therefore, the as-prepared activated carbons used as electrodematerials for the supercapacitors may exhibit excellent performance $[6-8,23]$.

The pore structure parameters of the activated carbons are summarized in Table 3. AC1 exhibits higher specific surface area and micropore volume while smaller mesopore volume and mesoporosity than $\mathrm{AC} 2$, indicating that the mineral matter in precursor facilitates the mesopores formation, however, suppresses the micropores formation that is tightly associated with specific surface area. Compared to AC2, AC3 shows approximately equal value of micropore volume, slight increase of specific surface area but significant increase in mesopore volume (nearly doubled), which suggest that the ash removal of activated carbon mainly influence the mesopore rather than micropore formation. In summary, among the three activated carbons, AC1 possesses the largest specific surface area of $492 \mathrm{~m}^{2} / \mathrm{g}$ and micropore volume of $0.2279 \mathrm{~cm}^{3} / \mathrm{g}, \mathrm{AC} 3$ possesses the largest total pore volume, mesopore volume and mesoporosity, and AC2 possesses the smallest specific surface area, total pore volume and micropore volume.

Potassium humate is a neutralized product of $\mathrm{KOH}$ and $\mathrm{HA}$ with a $\mathrm{KOH} / \mathrm{HA}$ mass ratio of about 0.12 . During carbonization of potassium humate, the small amount of potassium prefers to react with mineral matter to form mesopores, thus, the reaction between potassium and organic matter to create micropores is weakened. That is, the ash in potassium humate may suppress the formation of micropores and benefit the formation of mesopores. Obviously, the degree of reaction to make mesopores in commercial potassium humate is higher than that in pure potassium humate, which is contrary in terms of the reaction of forming micropores. AC3 exhibits more remarkable increment of mesopore volume than $\mathrm{AC} 2$, which is due to the micropore wall collapsing and template effect based on ash removal from AC2.

Table 3. Specific surface area and pore structure parameters of activated carbons

\begin{tabular}{|c|c|c|c|c|c|}
\hline Samples & $\begin{array}{c}S_{\mathrm{BET}}, \\
\mathrm{m}^{2} / \mathrm{g}\end{array}$ & $V_{\mathrm{t}}, \mathrm{cm}^{3} / \mathrm{g}$ & $\begin{array}{c}V_{\text {mic }}, \\
\mathrm{cm}^{3} / \mathrm{g}\end{array}$ & $\begin{array}{c}V_{\text {mes, }}, \\
\mathrm{cm}^{3} / \mathrm{g}\end{array}$ & $\begin{array}{c}\left(V_{\text {mes }}\right) / V_{t}, \\
\%\end{array}$ \\
\hline $\mathrm{AC} 1$ & 492 & 0.2498 & 0.2279 & 0.0217 & 8.7 \\
\hline $\mathrm{AC} 2$ & 421 & 0.2270 & 0.1916 & 0.0353 & 15.6 \\
\hline $\mathrm{AC} 3$ & 451 & 0.2599 & 0.1928 & 0.0670 & 25.8 \\
\hline
\end{tabular}

The surface morphologies of the samples are presented in Fig. 3. AC1 displays blocky structure with plenty of pores on its rough surface, which originates from the properties of potassium humate, i.e., certain order degree and relatively low ash content. AC2 exhibits three-dimensionally loose and amorphous structure with interconnected pores. AC3 shows the thick lamellar structure derived from aromatic units and these individual sheets associate with each other to form a continuous network.

The surface chemical compositions of activated carbons were analyzed by XPS measurements. As shown in Fig. 4, activated carbons all possess two main peaks located at the binding energy of about 285 and $533 \mathrm{eV}$, which correspond to the $\mathrm{C} 1 \mathrm{~s}$ and $\mathrm{O} 1 \mathrm{~s}$, respectively. The $\mathrm{C} 1 \mathrm{~s}$ spectrum can be approximately fitted into four main peaks located at the binding energy of $284.5 \mathrm{eV}, 285.2 \mathrm{eV}, 286 \mathrm{eV}$ and $289 \mathrm{eV}$, which is related to the $\mathrm{sp}^{2}$ hybridized carbon $(\mathrm{Cp} 1), \mathrm{sp}^{3}$ hybridized carbon (Cp2), $\mathrm{C}-\mathrm{O}(\mathrm{Cp} 3)$ as well as $\mathrm{C}=\mathrm{O}(\mathrm{Cp} 4)$ functional groups, respectively. The presence of oxygen containing functional groups can improve the wettability of activated carbons, and facilitate the penetration of electrolytes to pores.

\subsection{Electrochemical properties}

The carbon and oxygen contents of activated carbons are all in the range of $82.2-83.8 \mathrm{wt} . \%, 12.2-13.8 \mathrm{wt} . \%$, 
respectively, which demonstrate that the surface chemistry of the activated carbons are almost the same.

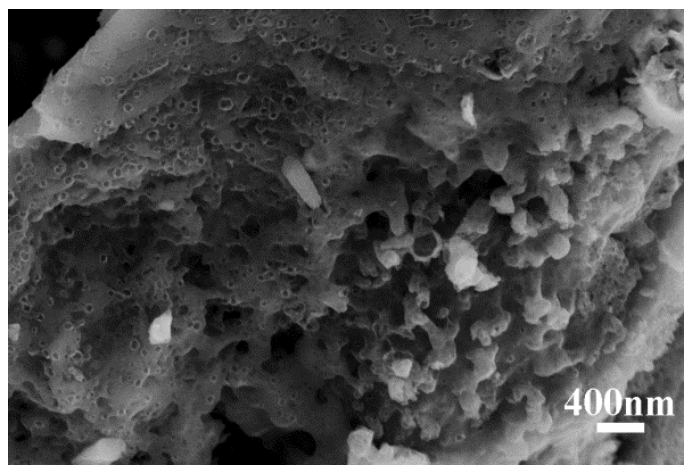

a

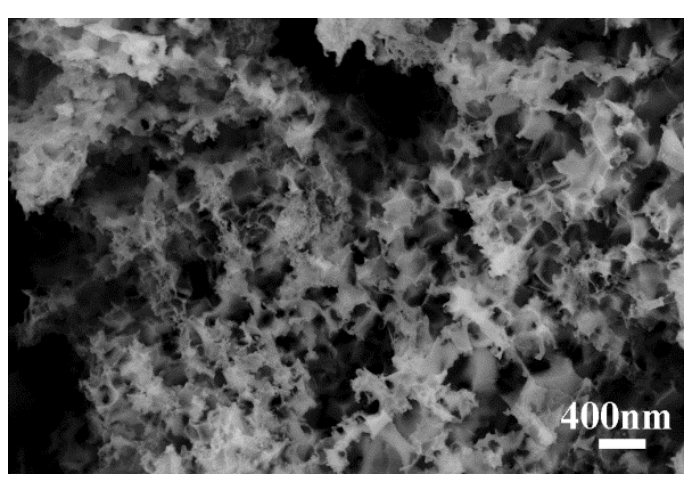

b

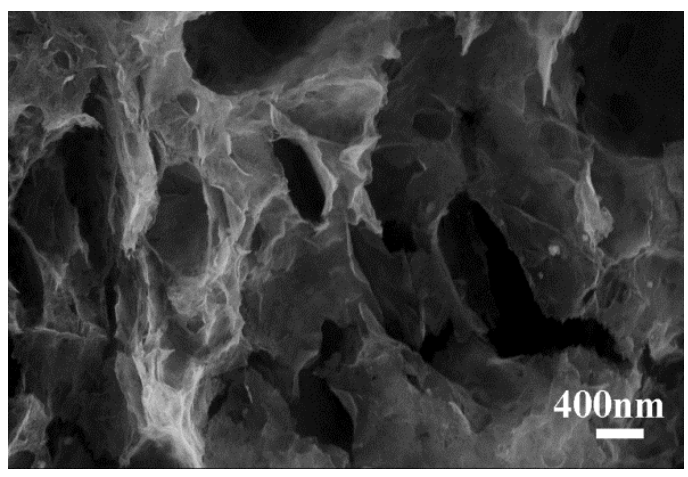

c

Fig. 3. SEM images of activated carbons: $a-A C 1 ; b-A C 2$; $\mathrm{c}-\mathrm{AC} 3$

Thus, the electrochemical properties of the samples may mainly depend on their pore structures and ash contents.

The GCD curves of the activated carbons as electrodes presented in Fig. 5 a exhibit typical triangular shapes without obvious voltage drop at the beginning of discharge, indicating the electrodes have the typical capacitive behaviors [21]. Moreover, the specific capacitances calculated from Eq. 1 are $164 \mathrm{~F} / \mathrm{g}$ for $\mathrm{AC} 1,110 \mathrm{~F} / \mathrm{g}$ for $\mathrm{AC} 2$ and $127 \mathrm{~F} / \mathrm{g}$ for $\mathrm{AC} 3$, respectively. It is known that micropores can provide electrode materials with a high accessible surface area for double layer capacitance. The three carbons have an order of AC1 $>\mathrm{AC} 3>\mathrm{AC} 2$ in terms of the specific capacitance, which agrees well with the order of the specific surface areas.

The CV curves of activated carbons at the scan rate of $1 \mathrm{mV} / \mathrm{s}$ (Fig. $5 \mathrm{~b}$ ) exhibit a quasi-rectangular shape without visible distortion, indicating the double layer capacitive behavior and excellent electrochemical reversibility, which is consistent with the results of GCD curves.
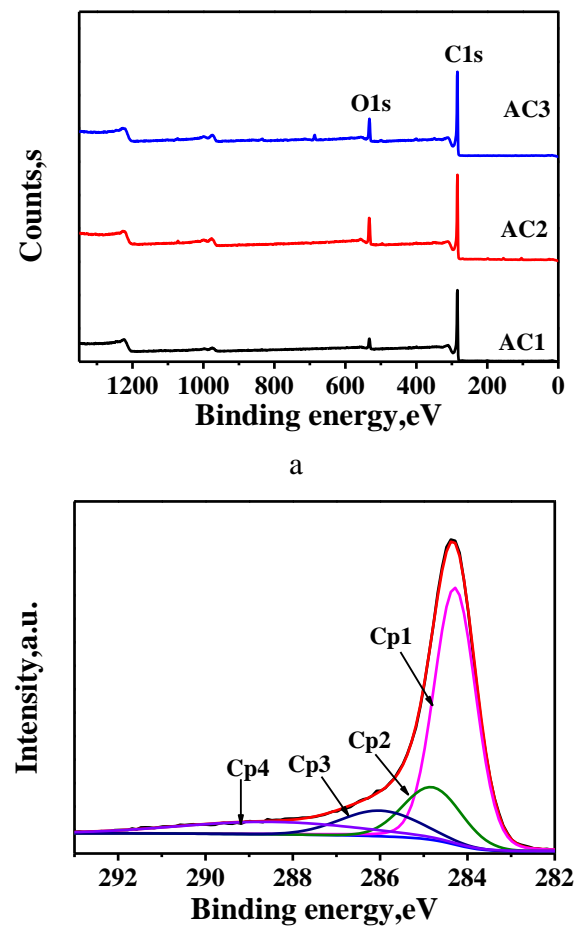

b

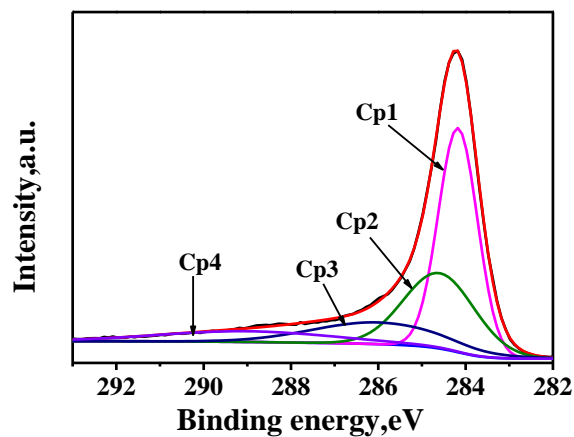

c

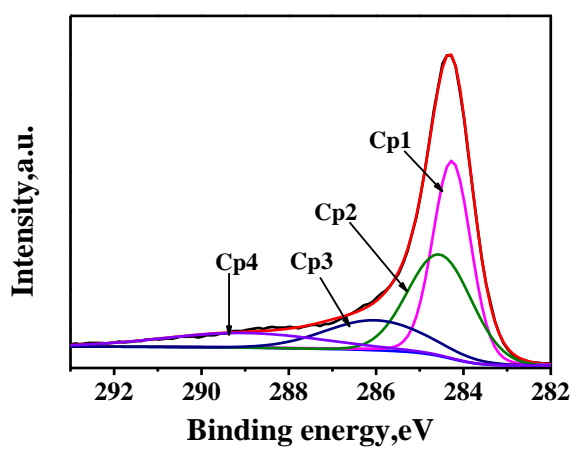

d

Fig. 4. $\mathrm{a}$-full-range XPS spectrum of activated carbons; $\mathrm{b}-\mathrm{C} 1 \mathrm{~s}$ XPS spectrum of $\mathrm{AC} 1 ; \mathrm{c}-\mathrm{C} 1 \mathrm{~s}$ XPS spectrum of $\mathrm{AC} 2 ; \mathrm{d}$. C1s XPS spectrum of AC3

Leakage current is a main parameter on practical applications of the EDLCs. As shown in Fig. 5 c, the leakage currents of $\mathrm{AC} 1$ and $\mathrm{AC} 3$ drop significantly from $0.906 \mathrm{~mA}$ to $0.104 \mathrm{~mA}$ at the beginning $17 \mathrm{~min}$, while that of AC2 is from $0.886 \mathrm{~mA}$ to $0.106 \mathrm{~mA}$ after $34 \mathrm{~min}$. Then they all gradually become smaller and more stable (finally to only $15.3 \mu \mathrm{A}$ for $\mathrm{AC} 1,25.0 \mu \mathrm{A}$ for $\mathrm{AC} 2$ and $17.3 \mu \mathrm{A}$ for AC3 after 5.4 hours, respectively). The leakage current 
behavior is related to the ash content, the values of leakage current and ash contents follow the same sequence of $\mathrm{AC} 1<\mathrm{AC} 3<\mathrm{AC} 2$. The smaller values of leakage current mean less shuttle reactions caused by the ashes in the activated carbons [21]. The less ash content, the smaller leakage current, which is in according to the results in the literature [12].

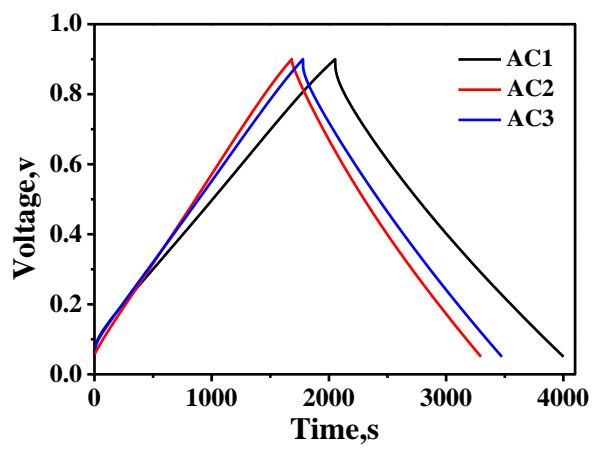

a

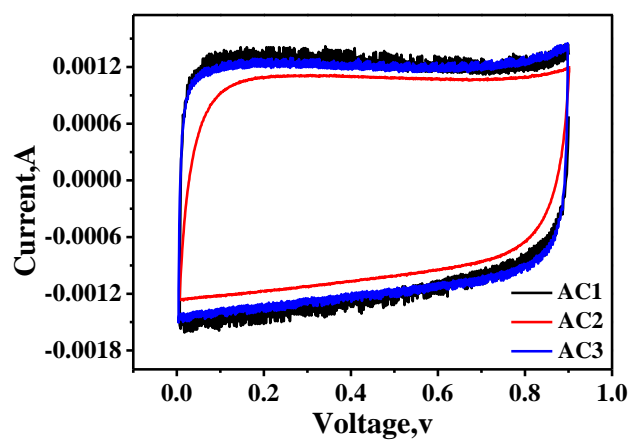

b

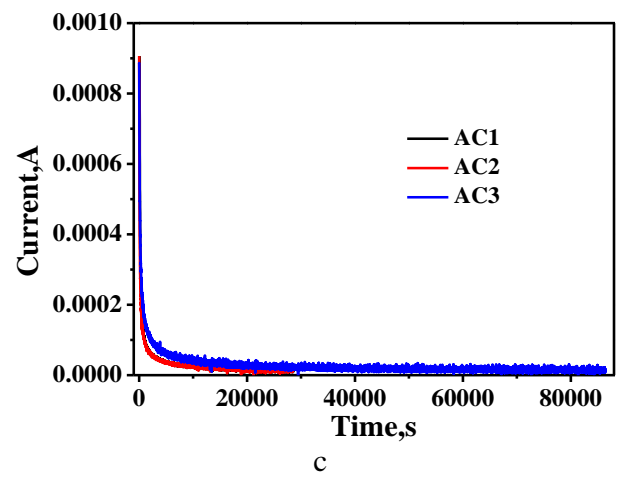

Fig. 5. a-GCD curves of activated carbons at $50 \mathrm{~mA} / \mathrm{g} ; \mathrm{b}-\mathrm{CV}$ curves of activated carbons at $1 \mathrm{mV} / \mathrm{s} ; \mathrm{c}$-leakage current curves of activated carbons

\section{Conclusions}

The ash removal methods have an important effect on ash content, pore structure and electrochemical performance of corresponding activated carbons for electric double layer capacitors. The process of ash removal before carbonization can better contribute to creating the micropores and ash removed after carbonization performs as templates to mainly generate mesopores. The activated carbons possess large specific surface area of $492 \mathrm{~m}^{2} / \mathrm{g}$, total pore volume of $0.2599 \mathrm{~cm}^{3} / \mathrm{g}$, and micropore volume of $0.2279 \mathrm{~cm}^{3} / \mathrm{g}$, respectively. The activated carbon $(\mathrm{AC} 1)$ with ash removed before carbonization as electrodes delivers a specific capacitance of $164.84 \mathrm{~F} / \mathrm{g}$ at a current density of $50 \mathrm{~mA} / \mathrm{g}$, and exhibits typical electric double layer capacitive performance as well as lower leakage current of $15.3 \mu \mathrm{A}$.

\section{Acknowledgements}

This work is financially supported by the National Natural Science Foundation of China (U1361119, 51404098, 51174077), the Foundation of Henan Polytechnic University for Ph. D (B2014-008), Natural Science Foundation of Henan province (162300410115), Key Scientific Research Project of Colleges and Universities in Henan Province (18A440002) and the research fund of Henan Key Laboratory for Green and Efficient Mining \& Comprehensive Utilization of Mineral Resources (Henan Polytechnic University).

\section{REFERENCES}

1. Meryl, S.P.Y.Z., $\quad$ Stoller, D. $\quad$ Graphene-Based Ultracapacitors Nano Letters 8 2008: pp. 3498-3502. https://doi.org/10.1021/n1802558y

2. Zhang, S., Pan, N. Supercapacitors Performance Evaluation Advanced Energy Materials 5 2015: pp. 1401401. https://doi.org/10.1002/aenm.201401401

3. Xing, B., Guo, H., Chen, L., Chen, Z., Zhang, C., Huang, G., Xie, W., Yu, J. Lignite-derived High Surface Area Mesoporous Activated Carbons for Electrochemical Capacitors Fuel Processing Technology 138 2015: pp. $734-742$. https://doi.org/10.1016/j.fuproc.2015.07.017

4. Long, C., Jiang, L., Wu, X., Jiang, Y., Yang, D., Wang, C., Wei, T., Fan, Z. Facile Synthesis of Functionalized Porous Carbon with Three-Dimensional Interconnected Pore Structure for High Volumetric Performance Supercapacitors Carbon 93 2015: pp. 412-420. https://doi.org/10.1016/j.carbon.2015.05.040

5. Zhang, Y., Zhang, C., Huang, G., Xing, B., Duan, Y. Synthesis and Capacitive Properties of Manganese Oxide Nanoparticles Dispersed on Hierarchical Porous Carbons Electrochimica Acta 166 2015: pp. 107-116. https://doi.org/10.1016/j.electacta.2015.03.073

6. Chen, X.Y., Song, H., Zhang, Z.J., He, Y.Y. A rational Template Carbonization Method for Producing Highly Porous Carbon for Supercapacitor Application Electrochimica Acta 117 2014: pp. 55-61. https://doi.org/10.1016/j.electacta.2013.11.098

7. Cheng, Q., Tang, J., Ma, J., Zhang, H., Shin, N., Qin, L. Graphene and carbon nanotube composite electrodes for supercapacitors with ultra-high energy density PHYS CHEM CHEM PHYS 39 2011: pp. 17615-17624. https://doi.org/10.1039/c1cp21910c

8. Inal, I.I.G., Holmes, S.M., Banford, A. Aktas, Z. The Performance of Supercapacitor Electrodes Developed from Chemically Activated Carbon Produced from Waste Tea Applied Surface Science 357 2015: pp. 696-703. https://doi.org/10.1016/j.apsusc.2015.09.067

9. Jin, H., Wang, X., Gu, Z., Polin, J. Carbon materials from High Ash Biochar for Supercapacitor and Improvement of Capacitance with $\mathrm{HNO}_{3}$ Surface Oxidation Journal of Power Sources 236 2013: pp. 285-292. https://doi.org/10.1016/j.jpowsour.2013.02.088

10. Wang, G., Zhang, L., Zhang, J. A Review of Electrode Materials for Electrochemical Supercapacitors Chemical Society Reviews 41 2012: pp. 797-828. https://doi.org/10.1039/C1CS15060J 
11. Braghiroli, F.L., Fierro, V., Szczurek, A. Stein, N., Parmentier, J., Celzard, A. Hydrothermally treated Aminated Tannin as Precursor of N-Doped Carbon Gels for Supercapacitors Carbon 90 2015: pp. 63-74. https://doi.org/10.1016/j.carbon.2015.03.038

12. Shao-yun, Z., Xin-hai, L., Zhi-xing, W., Hua-jun, G., Wen-Jie, P. Effect of Activated Carbon and Electrolyte on Properties of Supercapacitor Transactions of Nonferrous Metals Society of China 17 2007: pp. 1328-1333. https://doi.org/10.1016/S1003-6326(07)60271-4

13. Wasiński, K., Walkowiak, M., Lota, G. Humic acids as Pseudocapacitive Electrolyte Additive for Electrochemical Double Layer Capacitors Journal of Power Sources 255 2014: pp. 230-234. https://doi.org/10.1016/j.jpowsour.2013.12.140

14. Kumagai, S., Tashima, D. Electrochemical performance of Activated Carbons Prepared from Rice Husk in Different Types of Non-Aqueous Electrolytes Biomass \& Bioenergy 83 2015: pp. 216-223. https://doi.org/10.1016/j.biombioe.2015.09.021

15. Qu, W., Xu, Y., Lu, A., Zhang, X., Li, W. Converting Biowaste Corncob Residue into High Value Added Porous Carbon for Supercapacitor Electrodes Bioresource Technology 189 2015: pp. 285-291. https://doi.org/10.1016/j.biortech.2015.04.005

16. He, X., Li, R. Qiu, J., Xie, K., Ling, P., Yu, M., Zhang, X., Zheng, M. Synthesis of Mesoporous Carbons for Supercapacitors from Coal Tar Pitch by Coupling Microwave-Assisted $\mathrm{KOH}$ Activation with a $\mathrm{MgO}$ Template Carbon 50 2012: pp. 4911-4921. https://doi.org/10.1016/j.carbon.2012.06.020

17. Chen, H., Liu, D., Shen, Z., Bao, B., Zhao, S., Wu, L. Functional Biomass Carbons with Hierarchical Porous Structure for Supercapacitor Electrode Materials
Electrochimica Acta 180 2015: pp. 241-251. https://doi.org/10.1016/j.electacta.2015.08.133

18. Wasiński, K., Walkowiak, M., Lota, G. Humic Acids as Pseudocapacitive Electrolyte Additive for Electrochemical Double Layer Capacitors Journal of Power Sources 255 2014: pp. 230-234. https://doi.org/10.1016/j.jpowsour.2013.12.140

19. Xing, B., Guo, H., Chen, L., Zhang, C., Huang, G., Yi, G., Ma, M. Preparation of Oxygen-enriched Activated Carbons from Coal-based Humic Acids by Zinc Chloride Activation Current Nanoscience 11 2015: pp. 439-446. https://doi.org/10.2174/1573413711666150202234221

20. Huang, G., Kang, W., Xing, B., Chen, L., Zhang, C. Oxygen-rich and Hierarchical Porous Carbons Prepared from Coal Based Humic Acid for Supercapacitor Electrodes Fuel Processing Technology 142 2016: pp. 1-5. https://doi.org/10.1016/j.fuproc.2015.09.025

21. Zhang, Y., Zhang, C., Huang, G., Xing, B., Duan, Y. Tailoring the Textural Properties of Hierarchical Porous Carbons for Supercapacitors Materials Letter 159 2015: pp. 377-380 https://doi.org/10.1016/j.matlet.2015.07.020

22. Luo, H., Yang, Y., Chen, Y., Zhang, J., Zhao, X. Structure and Electrochemical Performance of Highly Porous Carbons by Single-Step Potassium Humate Carbonization for Application in Supercapacitors Journal of Applied Electrochemistry 46 2016: pp. 113-121. https://doi.org/10.1007/s10800-015-0894-0

23. Xing, B., Huang, G., Chen, Z., Chen, L., Yi, G., Zhang, C. Facile preparation of Hierarchical Porous Carbons for Supercapacitors by Direct Carbonization of Potassium Humate Journal of Solid State Electrochemistry 21 2017: pp. $263-271$. https://doi.org/10.1007/s10008-016-3360-y 